\title{
ADVANCE DIRECTIVES: A HELP OR A HINDRANCE TO PATIENTS AND DOCTORS?
}

\author{
J F Kelly, Consultant Surgeon, Lancaster and Kendal Hospitals
}

\section{INTRODUCTION}

The steady revolution in attitudes to patient autonomy, with increased information and participation in treatment decisions being demanded by patients, is only slowly being assimilated by some clinicians. It is the slow pace of these changes that has lead to the pressure for formal statements of patients' wishes, "living wills", in the event of their developing permanent or temporary incapacity so that they may retain some control over their treatment. The pace of ethical debate and the framing of legislation on these documents, which by their nature control "clinical freedom", is being forced in this country and abroad by non-medical bodies such as the House of Lords' Select Committee on Medical Ethics, the Law Commission and even the government itself through the Patients' Charter and the many other procedural standards that are being introduced. The medical profession has reacted with the production of The Code of Practice set out in the BMA's booklet "Advance Statements About Medical Treatment".

The definitions of the various forms of advance statements embraced by the term "living wills" and their legal status are set out in the BMA's booklet and other articles in this journal. To a clinician, the most important of the various forms of living will are Advance Directives which are statements of the refusal of treatment. Such statements carry the most serious legal liabilities for clinicians and can impose severe restrictions on clinicians' freedom.

Clinicians should surely welcome any help in understanding the hopes and aspirations of their patients particularly when the patient, due to illness, is unable to participate in rational discussion. The formalisation of attitudes, beliefs and objections to specific patterns of care ought to be of help in resolving difficult medical dilemmas particularly in the elderly.

But life is not quite so simple and the medical dilemmas that doctors face are not usually due to a lack of information about patients' wishes, but a lack of certainty about the ultimate outcomes of treatment. In the very elderly where the physical ravages of time cannot be reversed, many treatments (for example an amputation for an ischaemic limb) may have complications such as bronchopneumonia, bed sores or local infections which cause more discomfort and pain than the original condition and ultimately lead to the death of the patient. It cannot be considered good practice if the treatment causes more harm than the original illness, let alone fails to cure it.

\section{THE PUBLIC PERCEPTION OF DOCTORS}

The pressure for the introduction of "living wills" has been the public's impression that the medical ethic guiding the profession is the preservation and prolongation of life at all costs and the necessity for doctors to use the extremes of available technology to achieve that end. Hospital doctors, moreover, are perceived as being bound to prolong life whatever the physiological status, let alone the likely wishes of the patient. Doctors, are partly responsible for this mistaken impression. As a recent correspondent to the Voluntary Euthanasia Society (VES) Newsletter (Jan 1995) wrote "doctors, in order to give an air of optimism, put pressure on patients to accept treatment when there is no hope of recovery ... patients are given painful and traumatic treatment when there is no hope of recovery." This is the opposite of good practice and the ethic doctors should observe is never to carry out an action which harms their patients (enshrined in the Hippocratic oath); nor should they strive officiously to keep alive patients who are terminally ill. All treatment must potentially improve the quality of life and be administered only with the consent of the patient. These ethical principles should guide the holistic management of patients and most doctors so, in fact, seek the opinions of other doctors, and those of relatives and friends of patients who are incapable of participating in discussions about their care.

The poor impression of medical motives and conduct is bred of doctors' uncertainty about outcomes of treatment, and hopefully the development of clinical audit to assess the consequences of these interventions will help mutual understanding. Advance directives (refusals of treatment) for the moment may assist doctors by absolving them from having to make difficult decisions and insuring them against the consequences of failures to treat in specified circumstances.

But are the consequences of living wills always to a patient's advantage? Will they always be of assistance and should they be welcomed unreservedly by doctors?

\section{DANGERS TO PATIENTS}

Advance statements and advance directives are simple for patients to make and they must be taken into consideration by doctors. But the formulation of the expressed wishes requires very careful advice so that it is clear and unambiguous and has been made with all the appropriate information about the areas that the patient wishes to be addressed. The BMA booklet, highlights the need for adequate discussion and counselling to deal with the fears which create the desire to make such statements.

Such statements require regular updating and/or reconfirmation if they are to remain appropriate. All too often, parents instruct their children, when they are old enough to understand, how they wish to be dealt with in their later years when infirmity is likely to afflict them. Their instructions are made with intense loving consideration for their children and with the idea of releasing the children from the burdens of care when the parents grow old. But how different are the wishes of those same parents likely to be when they reach the 
predicted age? I still have the recorded message of my mother made in her 60 s stating her desire that we should place her in a convent nursing home when she became too infirm from her multiple sclerosis to live an independent life. At the age of 89 , however, and requiring round the clock nursing but still managing her financial affairs, she certainly expressed the opinion that it was inappropriate for her to be placed in a nursing home even for respite care.

The very existence of legalised formal statements holds particular dangers for patients themselves. They can be used by greedy attendants, confidantes and relatives to further their own ends. This not inconsiderable danger is recognised by the VES in their draft Bill for the legalisation of advance directives where the longest clause of ten sets out the penalties that should apply to falsification, tampering with, or coercion in the creation of an advance directive.

It is already a requirement for most hospitals in the USA to obtain consent to a simple living will outlining patients' consent to or refusal of invasive resuscitative treatment during their current admission. But this is a contemporaneous document produced by an independent agency and with a clearly stated duration of validity. The majority of us find making even the simplest of wills a daunting process. Regular revision is unlikely and critical events often forestall its appropriate revision. The principal motive for writing an advance directive is the fear of chronic incapacity and its effects on dignity.

Another difficulty for patients who wish to make advance directives is addressed in the BMA code. There is a danger that advance directives may take on a life of their own at crucial moments without the writer having foreseen the consequences. A doctor is trained to treat patients, particularly in emergencies or in the early stages of a terminal illness. There could be a misdiagnosis and time is needed for rational reflection on the consequences of treatment options. This safeguard which can be (and usually is) overidden when diagnoses are confirmed and patients' wishes known could almost automatically be abolished by advance directives.

The complexity of recovery in the relatively elderly from even minor curative operations can often prevent them for a short time from being involved in their own care. An advance directive may then be invoked by relatives even though the doctor anticipates a full recovery. Even while writing I have been asked by relatives to withdraw treatment because it seems "to be taking so long". The relatives are distressed, not the patient. In turn, the patient's natural depression about his slow progress reinforces the relatives' distress and their wish to intervene. Yet the patient has all the potential to return to the full and active life he lived before his admission.

For doctors, advance directives already have a life of their own. If doctors know or suspect that a patient has made an advance directive then they are obliged to seek for it and even emergency treatment may not be justified if it is known that the patient has objections to some or part of the treatment. If the incapacity to cooperate in decision-making is only temporary (eg because of anaesthesia or sedation) then only emergency life-preserving treatment may be justifiable and treatments that would otherwise be considered reasonable but not immediately essential may need to be postponed.

All doctors knowing the contents of an advance directive must judge its applicability in the circumstances and even if not directly applicable attempt to abide by its spirit.

In the case of the chronically ill there is time and opportunity to take advice and resolve difficulties by reference to other authorities or the courts. But in the complex situation of sudden, unanticipated emergencies advance directives can add enormous complications to the dilemma. Should one treat or not?

The decision to repair a leaking aortic aneurysm in the very elderly is always a difficult judgement which may be helped by an advance directive which refuses the intensive resuscitative interventions associated with intensive care. The same situation in a younger patient who has just signed an advance directive in anticipation of senility could delay appropriate care.

\section{DOCTORS AND THE LAW}

Those who believe the law can be refined to eliminate the conflicts that already exist must appreciate how imperfect an instrument is the law. It cannot possibly encompass every medico-social occasion and may confine the clinical freedom of doctors (see the article by David Lavelle).

There is a great deal of anxiety among many organisations that advance directives will open the door to the introduction of voluntary euthanasia. The BMA Code of Practice "seeks to divorce 'advance directives' from practices of euthanasia . . . and place them . . . within an accepted framework of discussion and communication". Advance directives, however, are championed by the VES with statements in its May 1995 newsletter on the Law Commission's March report headed "There's has been a "let me die' breakthrough". In debates on euthanasia a secretary of the society has pressed advance directives as an essential first stage in demonstrating patients' long-term expressed wishes to have their lives shortened in the event of chronic incapacity. This is in line with one of the criteria for permissible euthanasia in Holland namely, the established and persistent expressed desire of the patient. Although the law does not permit doctors assisting the death of patient (even if an advance directive requested it) such a document might have a very significant effect on a sympathetic doctor and a sympathetic court should it come to its attention. This scenario has remarkable echoes of the process which has led to the acceptance of euthanasia in Holland. The acknowledgement of the BMA's concern to divorce advance statements from euthanasia does not necessarily achieve this objective in the short or long term.

The Law Commission in its report proposed that there should be no opt-out clause for medical personnel who may have conscientious objections to advance directives. Even the BMA code supports the transfer of patients to another colleague in the event of such objections on the presumption that conscientious objection is likely to be a minority attitude and therefore a non-objecting colleague can always be found. In the particularly complex circumstances of acute incapacitating illness, therefore, more defined rules which will emanate from legislation on advance directives have the potential for greatly complicating treatment decisions and the anxieties these generate in all doctors. Every doctor needs to be an active participant in the debate if legislation is brought forward, because limitations on clinical decision- making by legal frameworks and the enactment of legal penalties to support such frameworks are more likely to frustrate communication and balanced medical judgement in critical medical situations.

Although potentially very helpful, advance directives may hinder appropriate and timely medical care. We should not, however, consider them completely benign instruments, and should recognise their potential for being manipulated, particularly if their legal status is changed. 